EPiC Series in Education Science
Volume 3, 2020, Pages 224-233
Proceedings of the MIT LINC 2019 Conference

\title{
Inclusivity through Asynchronous Interactions that Extend Past Barriers to Education
}

\author{
Jonathan S. Spackman, Ph.D. \\ Brigham Young University \\ jss@byu.edu
}

\begin{abstract}
This paper explores a case study of how educators reach out to and edify individuals behind barriers to educational opportunities. The scope of this paper does not address all barriers to education, but researches three: distance as a barrier that keeps a student physically distanced from the classroom, time as a barrier that forces communication to be asynchronous, and extendibility as a barrier that begs the question, "Can a teacher's influence be satisfactorily extended through the barriers of distance and time?" Edifying, within this interpretive frame, is defined as inviting the alma mater presence, guiding the learning experience, and revealing the previously out of reach or concealed context to the learner. Through an examination of artifacts and conducting of interviews, five themes describe how one organization successfully reaches out to and edifies learners behind the barriers of distance, time, and extendibility. These themes are the significance of feedback, overcoming the burden of asynchronicity, genuine concern for the student, true to brand, and cost consciousness.
\end{abstract}

\section{Introduction}

Imagine rebirth with more understanding, capacity, originality, self-purpose, liberty, charity, gratitude, joy, and community. The actuality of such a rebirth is as ordinary as the act of learning. Learning is the largely invisible and synchronized passing away and rebirth of oneself - a repeatable cycle representing the totality of life's experiences. As one learns, the self without the benefit of that learning dies and the self with the benefit of that learning is born. Philosophers such as Hegel and Heidegger mention our ability to remake ourselves in this way; but regardless of their streams of persuasive reasoning, all who have experienced learning can easily identify their new and improved self, when they remember their past. (Hegel, 1977; Heidegger, 1962) Learning can be for all who break free from the habits of underactive curiosity and trivial stimulations. Learning can energize the upward realizations of potential. Such potentials include improvement in evaluating, solving, creating, organizing, adapting, fixing, working, debating, choosing, loving, leading, and managing, among many, many others. These improvements are seen as shifts in one's capability following the hermeneutic 
traditions (for more details see the works of Merleau-Ponty (1962), Heidegger (1962), Dreyfus (1991), and Faulconer and Williams (1985)). However, the learner's pursuit is rarely, if ever a lonely path.

Learners for centuries have sensed a nurturing spirit accompanying this rebirth cycle; so much so, the honorable title of mother explains this transcendent presence. One's alma mater, nurturing mother, holds an exalted position in the life of an alumnus, one who was nurtured. The spirit of one's alma mater often runs very deep in the personality of the alumnus. Many universities claim the title of alma mater, but the principal investigator posits that whenever and wherever the symbolic rebirth through learning occurs, there may exist an often unidentified alma mater nurturing the learner. It could be an organization, a person, an artifact, a feeling, or an experience.

Education conceived as the cumulative results of these rebirths and improvement experiences through learning empowers individuals. There is ample evidence of this empowerment in the correlations between education and other situations such as poverty, democracy, marriage, and health. "In short, a strong linear relationship between education and earnings is envisaged...The economics of education is abundant with studies that firmly establish the correlation between education and earnings - earnings rising with increase in education levels, not rarely but almost universally and quite steeply and systematically." (Tilak, 2002) "Across the world, the correlation between education and democracy is extremely high" and education "increases the likelihood of successful democratic revolutions against dictatorships and reduces that of successful anti-democratic coups." (Glaeser, Ponzetto, \& Shleifer, 2007) "Divorce hazards are highest in marriages involving low education agents and lowest when the two partners are highly education." (Bruze, Svarer, \& Weiss, 2014) "The magnitude of the relationship between education and health varies across conditions, but they are generally large" such as the better educated the more likely to exercise, obtain preventive care, use seat belts, and have a smoke detector and the less likely to be hypertensive, suffer from emphysema or diabetes, report themselves in poor health, and call in sick at work. (Cutler \& Lleras-Muney, 2006)

When driven by the goal to empower individuals to improve their lives and communities; educators allow their talents to be utilized for meaningful societal pursuits. Armed with a firm grasp of how to invite the alma mater presence, how to guide the learning experience, and how to reveal the previously out of reach or concealed context to learners; educators edify individuals. However, barriers to this edification exist, as educators know, that represent challenges to inclusivity of all willing learners. The scope of this paper does not address all barriers to education, but explores three: distance, time, and extendibility.

Garrison, Anderson, and Archer reasoned that the best educational model for removing the barriers of distance and time was the independent study model because of its defining feature - asynchronous interactions through electronic communication or mail. (Garrison, Anderson, \& Archer, A Theory of Critical Inquiry in Online Distance Education, 2003) With asynchronous interactions, neither the educator nor the learner need to be in the same place or communicating at the same time; thus, removing the barriers of distance and time. A historic example of an educator who extended her influence to a learner behind the barriers of distance and time is the External Programme at the University of London. Nelson Mandela, while imprisoned, earned a law degree through the Programme's independent study courses. In its history, six other Nobel Prize winners earned degrees through the Programme's independent study courses; examples of human potential that may have been left unrealized without these asynchronous student-educator interactions. Properly designed asynchronous interactions hold the promise of being inexpensive, highly accessible, and span cultural and geographic boundaries, but can they satisfactorily extend the teacher's influence or are they sub-par? (Anderson, 2008, 2016; Garrison, 2011; Groves, 2012)

At the heart of the barrier of extendibility is the question: Can a teacher's influence be satisfactorily extended using asynchronous interactions? The independent study model and its defining feature, asynchronous interactions, reaches learners behind the barriers of distance and time, but what is the quality of those interactions? Does the quality of these kinds of interactions sufficiently edify learners? Is it probable for educators to reach those learners in a way that invites the alma mater presence, guides 
the learning experience, and reveals the previously concealed context to the learner? Although great debates have filled the literature regarding these questions; it is notable that even Charles Dickens had an opinion about the worth of extendibility. He called the University of London "The English People's University." He wrote, "The Oxford don may smile over his old port at [the People's] university that will extend her hand and offer a firm grip even to the young shoemaker who studies in his garret. [The Oxford don] may feel a little scornful of [the People's] university that, to the poor as to the rich, gives the man with few opportunities, as to the man with many, a free chance of obtaining, at the cost of hard toil and years of self-denial, the name and rank of a scholar." (Dickens, 1859) Dickens does not comment on the quality of asynchronous interactions, but scorns the scholars of his day for not providing the opportunity for learning to the distance student. Simply stated, he believed that once educated, it is the responsibility of the fortunate learners, not to set themselves apart, but to share the opportunity with others to include them in the community of learners.

\section{Method}

\subsection{Research Question}

How does an educator invite the alma mater presence, guide the learning experience, and reveal the previously out of reach or concealed context to specific learners that find themselves behind the barriers of distance, time, and extendibility? The remainder of this paper is a case study of one such educator that attempts to overcome these barriers - Brigham Young University's High School Independent Study courses ("BYU HS IS").

\subsection{Case Study Method}

Merriam's case study approach was used because the unit of study (i.e., BYU HS IS) was (1) well defined and bounded, (2) the research question invited inquiry and interpretation rather than hypothesis testing, (3) the unit of study was a particular case of the phenomenon being studied, and (4) the unit of study was likely to reveal important aspects of the phenomenon. (Merriam, 2001) The phenomenon was defined as the educators' attempts to edify learners that find themselves behind the barriers of distance, time, and extendibility. The interpretive frame throughout the case study was based on the act of edifying. Edifying, within this interpretive frame, was defined as inviting the alma mater presence, guiding the learning experience, and revealing the previously concealed context to the learner. This case study was not a test of this interpretive frame, but rather the interpretive frame was assumed to be a plausible way of producing themes related to the phenomenon. The unit of study provided a real-life example of the phenomenon; and thus, provided an expanded, holistic understanding. However, using the case study results, as a whole, should be limited from attempting to generalize or predict the future.

\subsection{Purposive Sample}

Based on purposive sampling methods, information-rich artifacts were examined and key interviews were conducted. (Patton, 2002) Specifically, the artifacts included program self-study documents and student survey results. The interviews conducted were with instructors and key program administrators within the areas of instructional design, educational support, product management, multimedia development, and administration. 


\subsection{Examination of Artifacts}

The principal investigator obtained and examine artifacts selected to define and bound the case to be studied. These artifacts provided background and context. According to the 2015 self-study documents, BYU HS IS courses were produced and administered within the Division of Continuing Education at Brigham Young University, which was established in 1921 to provide extension courses to neighboring towns. These courses were designed to be for the student population at a distance from the teacher and were working asynchronously with the teacher. At the time of this self-study, BYU HS IS had approximately 90,000 total enrollments. BYU Independent Study has experienced growth of approximate $115 \%$ over the last 15 years, according to the study. In 2015 , there were 48 full-time employees and approximately 300 BYU student and part-time employees dedicated to 228 BYU HS IS courses as instructional designers, artists, instructors, tutors, teaching assistants, student support phone representatives, marketing specialists, technical support specialists, and administrators. There were also several supporting service areas such as finance, human resources, registration, computer operations, and a dean's office. Several systems were utilized in conjunction with BYU HS IS such as custom registration system, Agillix Buzz/Brainhoney learning management system, Canvas learning management system, Microsoft Dynamics customer relations management system, virtual data center, PeopleSoft budgeting, forecasting, and hiring systems, Drupal website management system, Slack instant messaging, and Microsoft Teamwork project management system. The mission of BYU Independent Study was "BYU Independent Study partners with the university to develop and support educational experiences for students that spiritually strengthen, intellectually enlarge, build character, promote lifelong learning and service, and advance BYU's culture and institutional values within and beyond the physical campus." The BYU HS IS courses were accredited by AdvancEd, a national independent accrediting body for high schools.

BYU HS IS courses contained an end-of-course survey. In the 2015 self-study, it was reported that 17,236 students submitted completed surveys that year. Approximately $75 \%$ gave their instructor a "good" or higher rating, $88 \%$ indicated they were satisfied with their overall experience, $92 \%$ felt they had achieved their goals, $81 \%$ noted they had learned a great deal, and $90 \%$ agreed their experience contributed to being spiritually strengthened, intellectually enlarged, built their character, and promoted lifelong learning and service (in alignment with the BYU HS IS mission). These survey results were monitored bi-weekly for course-specific trends by an assessment team. The overall completion rate and pass rate were $96.7 \%$ and $87.0 \%$, respectively.

\subsection{Interviews}

The principal investigator interviewed each interviewee for 30 minutes. Informal conversation and semi-structured designs were used in the interviews. (Gall, Gall, \& Borg, 2003) These designs were intended to limit directive bias by the interviewer and to allow the interviewee to provide lightly guided coverage of a topic. (Turner, 2010) The principal investigator asked five general questions in each interview:

1. Tell me about your involvement in administering the BYU High School Independent Study courses.

2. Tell me about your involvement in helping invite the alma mater presence (nurturing mother) of BYU within the BYU High School Independent Study courses.

3. Tell me about your involvement in guiding the learning experience of students taking BYU High School Independent Study courses.

4. Tell me about your involvement in helping present the course content in a way that facilitates learning to students taking BYU High School Independent Study courses. 
5. What else would you like to tell me about BYU High School Independent Study courses?

The principal investigator asked follow-up questions to clarify answers and solicit more details. Based on purposive sampling methods, the interviewees were selected from different functional areas of BYU HS IS for the purpose of coverage. (Patton, 2002) Interviewees were volunteers and were not compensated. Interviewees included two instructors, product development administrator, testing manager, instructor support manager, student services manager, tutoring and teaching assistants manager, tutor, instructional design manager, instructional designer, media manager, and videographer. Interviews were audio recorded and transcribed. The principal investigator employed widely-accepted qualitative procedures of trustworthiness. (Lincoln \& Guba, 1985; Morrow, 2005) Each interviewee was given a copy of the interview transcript and invited, as a member check, to make any edits to improve clarity and accuracy. A peer debriefing was also conducted. Other procedures included negative case analysis, progressive subjectivity checks, and a confirmability audit. The Institutional Review Board of Brigham Young University approved the study.

Glaser and Strauss (1967) developed the constant comparative method as part of their grounded theory approach. Comparing all kinds of data by reading, rereading, coding, recoding, memo writing, and interpreting illustrates this approach. It can be said, that the principal analysis tool in this approach is the researcher's ability to constantly compare all data and summarize into delineated themes. The principal investigator read and reread the self-study, survey results, and interview transcripts; and coded and recoded until tentative themes began to emerge. Themes were then solidified by writing, rewriting, and interpreting at the same time as the principal investigator was performing progressive subjectivity checks. Once themes were somewhat solid, the principal investigator looked for negative cases and analyzed them.

\section{Results}

This research attempted to answer the following question: How does an educator invite the alma mater presence, guide the learning experience, and reveal the previously out of reach or concealed context to specific learners that find themselves behind the barriers of distance, time, and extendibility? BYU HS IS lent itself to being a good case for studying this research question because its courses were designed for the student population behind these barriers. It also made a good case because of its apparent success in educating student populations behind these barriers based on its enrollment history, mission, and student survey results. The principal investigator also identified various themes from the interviews that capture the essence of how BYU HS IS invited the alma mater presence, guided the learning experience, and revealed the previously out of reach or concealed context to this distant student population.

\subsection{Theme 1: The Significance of Feedback}

Through the data analysis, the principal investigator encountered evidence of the significance of feedback. The theme of feedback was so dominant; some might say the activities of BYU HS IS revolved around feedback. It was clear in the interviews that several kinds of feedback were frequent and highly valued.

Instructor, tutor, teaching assistant, and student services feedback to students were, by several interviewees, described in terms of direct, fast turnaround, short response times, solving problems immediately, helping with student goals, listening to students, reinforcement, strengthening the character of students, helping students solve their problems, consistent, and not slowing down learning. Feedback to students also included messages about consequences, deadlines, and setting schedules as a way to head off common problems with self-paced courses. Training about how to provide feedback to students was on going and included valuing attributes such as friendly, inviting, welcoming, open, 
kind, helpful, and supporting. There was an obvious priority placed on fast turnaround of assignments and exams with an underlining goal of keeping the student from wondering what the instructor was thinking or how the grade was determined. Overarching all of the feedback provided to students was the idea of helping the students feel a positive connection with BYU HS IS.

Another highly valued feedback was comments from students. Student feedback came in various forms including: (1) a call to student services, (2) an email to the instructor, and (3) the end-of-course survey. All calls to student services were logged and analyzed in the Microsoft Dynamics customer relation management system, which were reported out to various functional areas. Plainly visible goals included having an email to an instructor handled quickly by the instructor or quickly passed on to an instructor support employee. The results of the end-of-course survey were analyzed bi-weekly for rotating specific courses. Action lists were created to address the feedback from the surveys, when needed. Several interviewees press upon the principal investigator the seriousness in which student feedback was considered.

Instructors were part-time employees. Various functional areas sought after their feedback and considered it essential to operations. Instructional designers, media producers, tutors, teaching assistants, and student services considered the course a "living thing" requiring continuous feedback from the instructor. Instructors were encouraged to bring their asynchronous experiences, both good and bad, to a continuous design collaboration process.

BYU HS IS employees were encouraged to collaborate. The principal investigator noted the use of Slack instant messaging, Microsoft Teamwork project management system, and cross-functional meetings. Interviewees expressed the importance of topics being discussed in these forums such as concerns about keeping up with the times, completion rates, quality content, economic approaches to delivery of courses, and types of students. Active, animated discussions seemed to spring from employees' general satisfaction with the job and their opining the mission was meaningful and important. Comments were made such as "I'm a believer", "true fan", "we want the student to do well", and "a lot of thought goes into our courses." Also, when employees leave for other employment, exit interviews are conducted to gather feedback, which illustrated the important placed on employee feedback.

A robust data gathering process was in place to analyze data coming from the courses. Numerous data elements were analyzed to continuously improve the students experience and meet standards. Data seemed to be important to most interviewees.

\subsection{Theme 2: Overcoming the Burden of Asynchronicity}

In order to reach the student population behind the barriers of distance, time, and extendibility, BYU HS IS course designers and instructors had the burden of creating courses with completely asynchronous interactions; a burden that was not taken lightly. It appeared to take rigorous creativity to design quality learning experiences of this nature. Instructors and instructional designers as well as media producers were irreplaceable in accomplishing the instructional goal to "make the course be enough," that is, the course on its own should be very explanatory, clear, have visual cues, common symbols, and understandable without help, even though help was always to be provided. The standard for the design and smooth flow of these courses seemed to be "no hand raising [should be] required," even though the instructor, teaching assistants, tutors, and student support were available to answer questions. That type of design required all involved in the creation to anticipate and identify student problems. Over time, as they continuously collaborated with instructional designers, media producers, tutors, teaching assistants, student services, instructors, and students, based on the artifacts and interviews, their courses were incrementally changed to better attempt to carry the burden of asynchronicity. 


\subsection{Theme 3: Genuine Concern for the Student}

Encompassing most of what each interviewee said was another theme: the genuine concern for the student, their goals, their success, and their character development. The principal investigator observed a word used by several interviewees: advocate. The notion of being a student advocate came across strongly as interviewees talked about feedback, course design, student services, and filling gaps between the students and their goals. It was well understood by interviewees that asynchronous students needed to feel connected, supported, and heard. Training for student support representatives included how to pay close attention to student emotions and to advocate for the students when it came to pacing needs, technical support issues, course problems, and their learning goals. At the same time, employees counseled students about consequences, deadlines, setting schedules, and substantiating learning to help build the students' characters. Student success seemed to be a very high priority.

\subsection{Theme 4: True to Brand}

Brigham Young University is a private school with close ties to the Church of Jesus Christ of Latterday Saints. Anything branded BYU was expected to align with standards such as the honor code and ecclesiastical beliefs; however, the BYU HS IS courses were designed to reach out to and be inclusive of all students. Their form and content were secular, that is, following national and state standards. That said, branding them BYU meant to the interviewees that the courses needed to be special. They needed to be BYU. Some interviewees described the design of balancing both inclusivity and specialness as a focus on the uplifting, clean, conservative, scrubbed, pleasant, consistent, and noncontroversial. Some described it as helping the students "think up, think higher," think about the future, and think more positively without regard to religion. Training for instructors, tutors, teaching assistants, media producers, instructional designers, and student support included what the BYU brand means and how to stay true to its reputation while creating and supporting courses for anyone.

\subsection{Theme 5: Cost Consciousness}

A final major theme emerged. The principal investigator noted several interviewees' concern for keeping the cost of the courses down. It seemed that across the many functional areas of the interviewees, there was a common understanding that the asynchronous, distant student population needed a low cost accredited option to meet their educational goals. The principal investigator sensed an ordinariness among the interviewees when it came to value, speed, and lack of unnecessary bells and whistles.

\subsection{Negative Case Analysis}

The principal investigator searched the artifacts and interview transcripts for elements that contradicted with these emerging themes. Although feedback was central to the activities of BYU HS IS, it was mentioned that feedback could be acted upon faster. Also, the emphasis on "secular-ness" of the BYU HS IS courses made it unclear if students really knew they were taking a BYU course. It was clear there was a genuine concern for students, but most interactions with students were reactive and the need for more proactive interaction was mentioned.

\section{Discussion}

Central to this study was the examination of a case (i.e., BYU HS IS) that illustrated how one organization was successfully including and educating student populations that found themselves 
behind the barriers of distance, time, and extendibility. The barriers of distance and time referred to instructors and students being located in different geographic locations and being available at different times. Asynchronous interactions allowed instructors to engage students behind these barriers. Taking on the edification interpretive frame for learning, that is, inviting the alma mater presence, guiding the learning experience, and revealing the previously out of reach or concealed context to the learner; enabled the principal investigator to examine the barrier of extendibility. In other words, the principal investigator gathered artifacts and conducted interviews to determine how one organization addressed student edification with asynchronous interactions. Simply stated, do asynchronous interactions edify students enough for such learning to occur?

In general, the self-study artifacts pointed to a high enrolling and well-resourced, accredited organization with a long history of administering courses with asynchronous interactions. According to the end-of-course survey data, students largely were satisfied with their course experiences. The overall completion rate and pass rate were $96.7 \%$ and $87.0 \%$, respectively. These were indicators of a successful program. The interview questions addressed edification and interviewees included two instructors, product development administrator, testing manager, instructor support manager, student services manager, tutoring and teaching assistants manager, tutor, instructional design manager, instructional designer, media manager, and videographer. Although these employees came from different functional areas, it was difficult not to see in their responses five resulting themes.

The five themes the principal investigator noted demonstrated how this organization edified students behind the barriers of distance, time, and extendibility. It should not be surprising that in order to reach and connect with this student population, feedback would be extremely significant (i.e., theme 1). Since this student population could not avail itself of the traditional feedback tool, that is, the classroom; alternative asynchronous feedback tools became essential for learning. Moreover, such feedback needed to be fast, accurate, and helpful. Interviewees made it clear that fast, accurate, and helpful feedback was an organizational priority linked to its success.

Tied to the lack of a classroom was the burden of asynchronicity (i.e., theme 2). Setting the design standard such that no proverbial hand-raising would be required made for courses that attempted to anticipate student questions and to provide relevant resources. This design standard appeared to be much higher and more complex for instructors and instructional designers to meet than a traditional classroom course design that likely expected hand-raising questions and built in classroom time for such clarifications. Without the luxury of the classroom, instructors and instructional designers bridged these clarification gaps - gaps typical in classroom instruction - with lots of examples, with multiple ways of approaching the same issue, and by anticipating student questions, among other things. Feedback from the students (i.e., part of theme 1) played an indispensable part in the improvement of these design approaches.

It could easily be suggested that a student behind the barriers of distance, time, and extendibility might feel somewhat alone. Interviewees mentioned their role as student advocates (i.e., theme 3). This advocating role appeared to be deliberate in addressing this student population's overall need to be connected and heard. BYU HS IS trained its employees on their advocate role and placed a high priority on helping students reach their educational goals.

Wrapped up in all of the comments made by interviewees was the idea of being true to BYU (i.e., theme 4) and the special treatment of students and of course design that required. The striving for adherence to national and state educational standards, including accreditation, while remaining aligned with BYU's honor code and ecclesiastical beliefs took great care. In business, it could be described as a differentiation strategy - something to set the courses apart from the competition, but interviewees considered it a deeper distinction. Never wanting to proselytize or preach, the interviewees; however, wanted students to be edified and uplifted by the courses. This was a tall order when designing a course for a secular subject; nevertheless, the challenge seemed to energize some interviewees.

Finally, many interviewees expressed a cost consciousness (i.e., theme 5) when it came to the student population behind the barriers of distance, time, and extendibility. It appeared natural for 
interviewees to respond to questions in terms of economic value. This might be an indication of the culture woven into BYU HS IS, that is, the desire to make education accessible to all (e.g., historic slogan: education anytime, anywhere, for anyone).

An implication of this study is a defense of asynchronous education. Some educational groups have historically downgraded asynchronous methods, leaning instead towards synchronous activities with the instructor via technology. These leanings replace the classroom with technology; thus, reaching students behind the barrier of distance. However, synchronous activities fail to reach the entire student population behind the barrier of time. Those students trapped in schedules that conflict with the instructor's schedule (e.g., previously mentioned Nobel prize winners) seem to be forgotten by some groups much like Dicken's version of the Oxford don, who is put out by the shoemaker wanting to be a scholar. Although the debate will likely continue for years to come about whether asynchronous interactions edify students, this paper presented one example of how it is being done today.

One limitation of this study was the lack of data regarding other organizations involved in asynchronous education. As a case study, the results should not be generalized to this industry. Future research of other organizations offering asynchronous education would enrich the field. Another question that was not answered by this paper, but should be researched is: Do asynchronous interactions reach past other educational barriers such as poverty, illiteracy, accessibility, political borders, failing schools, dangerous commutes, and shortages of experts? Answering these questions could extend the educational hand even further and firmly grip even more learners, as Dickens might put it.

\section{References}

Anderson, T. (2008). The Tehory of Practice of Online Learning. Athabasca University Press.

Anderson, T. (2016). Theories for Learning with Emerging Technologies. Emerging Technologies in Distance Education.

Bruze, G., Svarer, M., \& Weiss, Y. (2014). The Dynamics of Marriage and Divorce. Journal of Labor Economics, 33(1), 123-170. doi:10.1086/677393

Cutler, D. M., \& Lleras-Muney, A. (2006). Education and Health: Evaluating Theories and Evidence. National Bureau of Economic Research. doi:10.3386/w12352

Dickens, C. (1859). The English People's University. All the Year Round: A Weekly Journal, 279-283.

Dreyfus, H. L. (1991). Being-in-the-World: A Commentary of Heidegger's Being and Time. Division I. MIT Press.

Faulconer, J. E., \& Williams, R. (1985). Temporality in Human Action: An Alternative to Positivism and Historicism. American Psychologist, 40(11), 1179. doi:10.1037/0003-066X.40.11.1179

Gall, M. D., Gall, J. P., \& Borg, W. (2003). Educational Research: An Introduction. Boston: Person Education.

Garrison, D. R. (2011). E-learning in the 21st Century: A Framework for Research and Practice. Taylor \& Francis. doi:10.4324/9780203838761

Garrison, D. R., Anderson, T., \& Archer, W. (2003). A Theory of Critical Inquiry in Online Distance Education. Handbook of Distnace Education, 113-127.

Glaeser, E., Ponzetto, G., \& Shleifer, A. (2007). Why Does Democracy Need Education? Journal of Economic Growth, 12(2), 77-99. doi:10.1007/s10887-007-9015-1

Glaser, B., \& Strauss, A. (1967). Grounded Theory: The Discovery of Grounded Theory. The Journal of The British Sociological Association, 27-49.

Groves, N. (2012). Distance Learning: The Student who Combines education and Employment. The Guardian. Retrieved from https://www.theguardian.com/careers/distance-learning-universityof-london

Hegel, G. W. (1977). Hegel's Phenomenology of spirit. Clarendon Press. 
Heidegger, M. (1962). Being and Time. New York: John Macquarrie and Edward Robinson.

Lincoln, Y. S., \& Guba, E. G. (1985). Naturalistic Inquiry. Beverly Hills, CA: Sage Publications.

Merleau-Ponty, M. (1962). Phenomenology of Perception. (S. Colin, Trans.) Routledge \& Kegan Paul.

Merriam, S. B. (2001). Qualitative Research and Case Study Applications in Education. San Francisco, CA: Jossey-Bass Publishers.

Morrow, S. L. (2005). Quality and Trustworthiness in Qualitative Research in Counseling Psychology. Journal of Counseling Psychology, 52(2), 250-260. doi:10.1037/0022-0167.52.2.250

Patton, M. Q. (2002). Qualitative Interviewing. Qualitative Research and Evaluation Methods, 344347.

Tilak, J. B. (2002). Education and Poverty. Journal of Human Development, 3(2), 191-207. doi:10.1080/14649880220147301

Turner, D. W. (2010). Qualitative Interview Design: A Practical Guide for Novice Investigators. The Qualitative Report, 15(3), 754. 